\title{
Combined Cytolytic Effects of a Vaccinia Virus Encoding a Single Chain Trimer of MHC-I with a Tax-Epitope and Tax-Specific CTLs on HTLV-I-Infected Cells in a Rat Model
}

\author{
Takashi Ohashi, ${ }^{1}$ Takafumi Nakamura, ${ }^{2}$ Minoru Kidokoro, ${ }^{3}$ \\ Xianfeng Zhang, ${ }^{1}$ and Hisatoshi Shida ${ }^{1}$ \\ ${ }^{1}$ Division of Molecular Virology, Institute for Genetic Medicine, Hokkaido University, Kita 15, Nishi 7, Kita-ku, Sapporo, \\ Hokkaido 060-0815, Japan \\ ${ }^{2}$ Division of Integrative Bioscience, Department of Biomedical Science, Institute of Regenerative Medicine and Biofunction, \\ Graduate School of Medical Science, Tottori University, Yonago, Tottori 683-8503, Japan \\ ${ }^{3}$ Department of Virology III, National Institute of Infectious Diseases, Musashimurayama, Tokyo 208-0011, Japan
}

Correspondence should be addressed to Takashi Ohashi; ohashi-t@igm.hokudai.ac.jp

Received 12 December 2013; Accepted 20 February 2014; Published 27 March 2014

Academic Editor: Masahisa Jinushi

Copyright (C) 2014 Takashi Ohashi et al. This is an open access article distributed under the Creative Commons Attribution License, which permits unrestricted use, distribution, and reproduction in any medium, provided the original work is properly cited.

Adult T cell leukemia (ATL) is a malignant lymphoproliferative disease caused by human T cell leukemia virus type I (HTLV-I). To develop an effective therapy against the disease, we have examined the oncolytic ability of an attenuated vaccinia virus (VV), LC16m8 $(\mathrm{m} 8 \Delta)$, and an HTLV-I Tax-specific cytotoxic T lymphocyte (CTL) line, 4O1/C8, against an HTLV-I-infected rat T cell line, FPM1. Our results demonstrated that $\mathrm{m} 8 \Delta$ was able to replicate in and lyse tumorigenic FPM1 cells but was incompetent to injure 4O1/C8 cells, suggesting the preferential cytolytic activity toward tumor cells. To further enhance the cytolysis of HTLV-Iinfected cells, we modified $\mathrm{m} 8 \Delta$ and obtained m8 8 /RT1AlSCTax180L, which can express a single chain trimer (SCT) of rat major histocompatibility complex class I with a Tax-epitope. Combined treatment with m8 $\Delta / \mathrm{RT} 1 \mathrm{AlSCTax} 180 \mathrm{~L}$ and $4 \mathrm{O} 1 / \mathrm{C} 8$ increased the cytolysis of FPM1V.EFGFP/8R cells, a CTL-resistant subclone of FPM1, compared with that using 4O1/C8 and m8 presenting

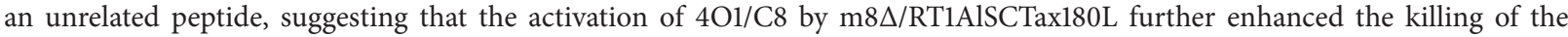
tumorigenic HTLV-I-infected cells. Our results indicate that combined therapy of oncolytic VVs with SCTs and HTLV-I-specific CTLs may be effective for eradication of HTLV-I-infected cells, which evade from CTL lysis and potentially develop ATL.

\section{Introduction}

Human T cell leukemia virus type I (HTLV-I) is etiologically linked to adult $\mathrm{T}$ cell leukemia (ATL) $[1,2]$ and a chronic progressive neurological disorder termed HTLV-I-associated myelopathy/tropical spastic paraparesis (HAM/TSP) $[3,4]$. HTLV-I genome contains a unique $3^{\prime}$ region, designated as $\mathrm{pX}$, which encodes the viral transactivator protein, Tax [5]. It is speculated that Tax plays a central role in HTLVI associated immortalization and transformation of $\mathrm{T}$ cells, which may lead to the development of ATL [6]. In addition, Tax is also known as a major target protein recognized by cytotoxic T lymphocyte (CTL) of HTLV-I carriers [7]. A number of studies have reported that CTL responses were activated in HAM/TSP patients but were weak in ATL patients, suggesting that the $\mathrm{T}$ cell response could be one of the important determinants of the disease manifestation [8]. Since HTLV-I Tax-specific CTL can recognize and lyse ATL cells in vitro [9], it is conceivable that the low CTL activity in ATL patients is disadvantageous as it may allow uncontrolled proliferation and evolution of HTLV-I-infected cells in vivo. Indeed, Hasegawa et al. have reported that oral HTLV-I-infection induced HTLV-I-specific T cell tolerance and caused an elevation of the proviral loads and that reimmunization resulted in the recovery of the virus-specific $\mathrm{T}$ cell responses and the decrease of the proviral loads in a rat model system [10]. In addition, the development of ATL has been reported in HTLV-I carriers who received immunosuppressants during organ transplantation [11]. Increase of Taxspecific CTLs observed in ATL patients treated successfully 
with allogeneic hematopoietic stem cell transplantation (alloHSCT) also suggests the importance of virus-specific CTLs to control the disease [12]. Thus, immune therapies to activate HTLV-I-specific CTLs are considered as novel attempts for the treatment of ATL. In this regard, we have previously demonstrated the therapeutic effect of Tax-coding DNA or peptide in a rat model of ATL-like disease $[13,14]$. In addition, it has been recently reported that autologous Tax-specific CTLs showed therapeutic benefits in an animal model using NOG mice bearing primary ATL cells, suggesting the possible translation into a clinical use [15].

To improve therapeutic effects of immune therapy, it is important to consider tumor microenvironment, because tumor cells often induce a microenvironment, which favors the development of immunosuppressive populations of immune cells, such as myeloid-derived suppressor cells and regulatory T cells [16]. In HTLV-I carriers and ATL patients, various kinds of immunosuppressive events have been reported, indicating the importance of developing new strategies to eliminate HTLV-I-infected cells in such immunosuppressive environments [8]. One of powerful strategies to lyse tumor cells in an immunosuppressive microenvironment would be the use of replication-competent oncolytic viruses, because oncolytic virotherapy has been known to induce both direct tumor killing and local proinflammatory environments that help to reverse the immunosuppressive environment of tumors $[17,18]$. As for HTLV-I infection, vesicular stomatitis virus (VSV) has been reported to have oncolytic activity against primary ATL cells [19]. Vaccinia virus (VV) has been also shown to be a good candidate for oncolytic virotherapies [20]. It has been already assessed in clinical trials and shown to selectively infect, replicate, and express transgene products in cancer tissues without damaging normal tissues [21]. We have previously constructed a highly attenuated $\mathrm{VV}, \mathrm{LC16m} 8 \Delta(\mathrm{m} 8 \Delta)$, which is genetically more stable than LC16m8 (m8), a naturally occurring counterpart of $\mathrm{m} 8 \Delta$, and less pathogenic than its parental $\mathrm{LC16mO}(\mathrm{mO})$ due to the deletion of B5R gene [22]. The safety of $m 8 \Delta$ has been already confirmed in clinical use of its natural counterpart; $\mathrm{m} 8$ has been safely administered to approximately 100,000 infants and 3,000 adults for smallpox vaccination and induced levels of immunity similar to those of the original Lister strain without serious side effects [23]. Moreover, Hikichi et al. have recently reported the oncolytic potential of $\mathrm{m} 8 \Delta$ with regulated expression of B5R [24]. Thus, the application of $\mathrm{m} 8 \Delta$ for the elimination of HTLV-I-infected cells should be possible.

It is well known that HTLV-I viral protein expression is suppressed in infected cells in the peripheral blood of the virus-infected individuals, probably due to either unidentified suppression mechanisms of HTLV-I expression or genetic and epigenetic changes in the viral genome [8]. This reduction of viral protein expression may cause the decrease of anti-HTLV-I immune responses. Downregulation of major histocompatibility complex class I (MHC-I) could also lead to the evasion of HTLV-I-infected cells from the virus-specific CTLs [25]. Thus, strategies to overcome the repression of viral antigen presentation in HTLV-I infected individuals should be also required to establish effective anti-HTLV-I therapies.
Improving the ability to present antigen to proper CTLs could be one possible way to overcome the problem. Single chain trimers (SCTs) of MHC-I have been reported to possess the strong potential to stimulate antigen-specific T cells $[26,27]$. In this system, all three components of MHC-I complexes, such as an antigen peptide, $\beta_{2}$-microgrobulin $\left(\beta_{2} \mathrm{~m}\right)$, and MHC-I heavy chain, were covalently attached with flexible linkers. By connecting together the three components into a single chain chimeric protein, a complicated cellular machinery of antigen processing can be bypassed, leading to stable cell surface expression of MHC-I coupled with an antigenic peptide of interest. It has been recently reported that SCTexpressing DNA vaccine is able to break immune tolerance against self-antigen from melanoma, further supporting the potential of SCTs to clinical applications [28]. By applying SCT system to a rat model of HTLV-I infection, we have previously developed an activation and detection system of Tax-specific rat $\mathrm{T}$ cells and showed that SCTs with a Taxepitope specifically recognize and activate Tax-specific CTLs [29]. In this study, to further improve the efficacy of CTL activation by SCTs, m $8 \Delta$ was selected as a vector to express SCTs on the surface of HTLV-I-infected cells. Introduction of SCT coding sequence into the genome of $\mathrm{m} 8 \Delta$ could generate novel therapeutic VVs, which possess abilities to both lyse tumor cells and activate tumor-specific CTLs. We further examined the combination effects of Tax-specific CTLs and m8 $\Delta$ expressing SCT against CTL-resistant HTLV-I-infected cells. Our results suggested the possible application of the combined use of oncolytic viruses presenting tumor antigens and tumor-specific CTLs for the treatments against tumors including ATL.

\section{Materials and Methods}

2.1. Cells and Viruses. An HTLV-I-immortalized cell line, FPM1, was previously established by cocultivating thymocytes of an F344/N Jcl-rnu/+ rat (Clea Japan, Inc. Tokyo, Japan) with HTLV-I producing human cell line, MT-2, which was treated with mitomycin $\mathrm{C}(50 \mu \mathrm{g} / \mathrm{mL})$ for $30 \mathrm{~min}$ at $37^{\circ} \mathrm{C}$ [30]. FPM1V.EFGFP, FPM1V.EFGFP/8R, and 4O1/C8 cells were established as previously described [25]. FPM1V.EFGFP was a subclone of FPM1 cells, which stably expresses EGFP. FPM1V.EFGFP/8R cells were generated from FPM1V.EFGFP cells, by continuously cultivating with a Tax-specific CTL, 4O1/C8, and obtained an ability to evade from CTL killing by 4O1/C8 cells. FPM1 and its subclones were maintained in RPMI 1640 with 10\% heat-inactivated FCS (Sigma-Aldrich, St. Louis, MO), $55 \mu \mathrm{M}$ of 2-mercaptoethanol (Gibco, Grand Island, NY), penicillin, and streptomycin. The 4O1/C8 cells were established from an F344/N Jcl-rnu/+ rat inoculated with Tax-coding DNA and were maintained in RPMI 1640 medium with $10 \%$ FCS, $55 \mu \mathrm{M}$ of 2 -mercaptoethanol, and $20 \mathrm{U}$ of IL-2 (PEPROTECH, London, UK) per $\mathrm{mL}$ with periodical stimulation using formalin-fixed FPM1 cells every 4 weeks. A rabbit kidney epithelial cell line, RK13, was cultured in RPMI1640 supplemented with 10\% FCS. Hamster BHK cells were cultured in D-MEM supplemented with $10 \%$ FCS. Canarypox virus (a kind gift of National Institute of Animal Health) [31], mO, m8s [22], and LC16 m8 VNC110 that harbors multiple cloning site in the HA gene of $\mathrm{m} 8 \Delta$ 
genome were described previously [32]. Viral titers were calculated on the basis of the number of plaques on RK13 cells.

2.2. Construction of $m 8 \Delta$ Expressing SCTs of Rat MHCI. The expression vectors, pEF/RT1AlSCTax180L and pEF/RT1AISCNLEnv371L, which encode SCTs of rat MHC-I with Tax180-188 (Tax180) or human immunodeficiency virus type 1 (HIV-1) NL43 Env371-379 (NLEnv371) epitopes, respectively, were previously constructed [29]. To generate $\mathrm{m} 8 \Delta$ expressing SCTs, peptide- $\beta_{2} \mathrm{~m}-\mathrm{RT1A}{ }^{1}$ fusion sequence in pEF/RT1AlSCTax180L or pEF/RT1AISCNLEnv371L was amplified by PCR to add CpoI and FseI sites at the $5^{\prime}$ and $3^{\prime}$ end of the fusion constructs, respectively, and were ligated into the LC16m8 8 VNC110 genome that had been digested with CpoI and FseI. The ligated DNA was transfected into BHK cells that were infected with canarypox virus, as described previously [32]. The recombinants were selected by plaque ELISA using an anti-rat MHC-I antibody (clone OX-18; BD PharMingen Co., San Diego, CA) and were then subjected to Western blotting to confirm the proper protein expression.

2.3. Protein Analysis. For plaque ELISA, recombinant VVs were infected to RK13 cells on 6 well plates at approximately $100 \mathrm{pfu} /$ well. After incubation for $72 \mathrm{~h}$ at $33^{\circ} \mathrm{C}$, the infected cells were fixed with $2 \%$ paraformaldehyde solution followed by permeabilization with $0.5 \% \mathrm{NP} 40$ for $1 \mathrm{~min}$. The fixed cells were blocked with 5\% skim milk in PBS for 30 min and incubated with an anti-rat MHC-I antibody (clone OX-18; BD PharMingen Co.) followed by incubation with an alkaline phosphatase-conjugated anti-mouse IgG antibody (SigmaAldrich). After staining with alkaline phosphatase substrates, the plaques with dark blue color were collected as positive clones.

For Western blotting, cells were resuspended in icecold extraction buffer (20 mM HEPES [pH 7.9], $10 \mathrm{mM} \mathrm{KCl}$, $1 \mathrm{mM} \mathrm{MgCl} 2,150 \mathrm{mM} \mathrm{NaCl}, 1 \%$ Triton X-100, $0.5 \mathrm{mM} \mathrm{DTT}$, $0.5 \mathrm{mM}$ PMSF, $1 \mu \mathrm{g} / \mathrm{mL}$ aprotinin, and $1 \mu \mathrm{g} / \mathrm{mL}$ leupeptin) and gently rocked for 30 minutes. After centrifugation at $14,000 \times \mathrm{g}$ for 20 minutes at $4^{\circ} \mathrm{C}$, the supernatant was collected as a whole cell extract. The protein concentration of each sample was determined using a BCA protein assay reagent kit (Pierce Biotechnology, Rockford, IL). Fifty $\mu \mathrm{g}$ of whole cell extracts was separated by $8 \%$ SDS-PAGE and transferred to a nitrocellulose filter. The filter was incubated with an anti-rat MHC-I antibody and then with an anti-mouse Ig antibody conjugated to horseradish peroxidase (Amersham, Arlington Heights, IL). Antibodies bound to the filter were detected by the enhanced chemiluminescence method (Amersham).

2.4. A Flow-Cytometric CTL Killing Assay. EGFP-expressing target cells $\left(2.5-5.0 \times 10^{4}\right.$ cells/well $)$ were cocultured with CTLs $\left(2.5 \times 10^{5}-1 \times 10^{6}\right.$ cells/well). These mixed cultures were immediately subjected to flow-cytometric analysis or were incubated for indicated days and then subjected to flow-cytometric analysis. Cytofluorometry was done on a FACSCalibur (BD Biosciences, San Jose, CA) and analyzed with Cell Quest software. Target cells were clearly gated away from CTLs by light-scatter properties and EGFP expression.
2.5. IFN- $\gamma$ Production Assay. The 4O1/C8 $\left(1 \times 10^{5} /\right.$ well $)$ was mixed with various stimulator cells $\left(2 \times 10^{4} /\right.$ well $)$. After indicated period of mixed culture, supernatants were harvested and subjected to rat IFN- $\gamma$ ELISA (eBioscience Inc., San Diego, CA) in accordance with the manufacturer's instructions.

2.6. Cell Viability Assay. Cells were infected with VVs and then incubated for indicated periods. In some experiments, cells were stimulated with formalin-fixed FPM1 cells for 2 days and then infected with VVs. The number of growing cells was determined by using a cell counting kit-8 (Dojinndo Laboratories, Kumamoto, Japan) in accordance with the manufacturer's instructions. Cell viabilities are expressed as percentages of cell survival of mock-infected cultures, as described previously [24].

2.7. Statistical Analysis. Comparisons between individual data points were made using a Student's $t$-test. Two-sided $P$ values $<0.05$ were considered statistically significant.

\section{Results}

3.1. Rat HTLV-I-Infected Cells Were Susceptible to the Killing by Attenuated Vaccinia Strain, $m 8 \Delta$. To develop a safe and effective smallpox vaccine and vector virus, we have previously constructed genetically stable $\mathrm{m} 8 \Delta$, which is less pathogenic than its parental $\mathrm{mO}$ due to the deletion of B5R gene [22], and successfully applied it for animal studies of HIV-1 vaccine developments [32-34]. In this study, to determine whether $\mathrm{m} 8 \Delta$ possesses cytolytic activity against HTLV-I-infected cells, a rat HTLV-I-infected cell line, FPM1 was infected with $\mathrm{m} 8 \Delta$ or $\mathrm{mO}$. As shown in Figure 1(a), we observed the gradual reduction of cell viability in FPM1 cells infected with $\mathrm{m} 8 \Delta$ at multiplicity of infection (MOI) 0.1 and confirmed the significant difference in cell viability between m8 - and mock-infected cells at 4 days after infection, indicating the induction of cytolysis of FPM1 cells by $\mathrm{m} 8 \Delta$. The cytolysis induction by $\mathrm{mO}$ was more efficient than that by $\mathrm{m} 8 \Delta$ at MOI 0.1 , because significant difference in cell viability was observed after 2 days of infection. Similar levels of significant cytolysis induction were observed in FPM1 cells infected with either $\mathrm{m} 8 \Delta$ or $\mathrm{mO}$ at MOI 0.5 . We next examined the virus replication in the cells infected with VV at MOI 0.1 and confirmed $2.1 \times 10^{3}$ and $1.2 \times$ $10^{4}$ fold increase of infectious $\mathrm{m} 8 \Delta$ and $\mathrm{mO}$, respectively, at 3 days after infection (Figure 1(b)). These results indicate that the attenuated $m 8 \Delta$ possesses lower level of oncolytic activity compared with its parental $\mathrm{mO}$ and that increasing the virus inoculum can compensate the reduced activity. In addition, we have maintained the virus-infected cells for extended periods and confirmed that all the cells used in Figure 1(a) were eventually killed by VVs (data not shown). Thus, prolonged cultivation could also improve the efficacy of oncolysis by highly attenuated VVs.

3.2. A Tax-Specific CTL Line, 4O1/C8, Was Resistant to Killing by $m 8 \Delta$. Virus-specific CTLs that play important roles in 

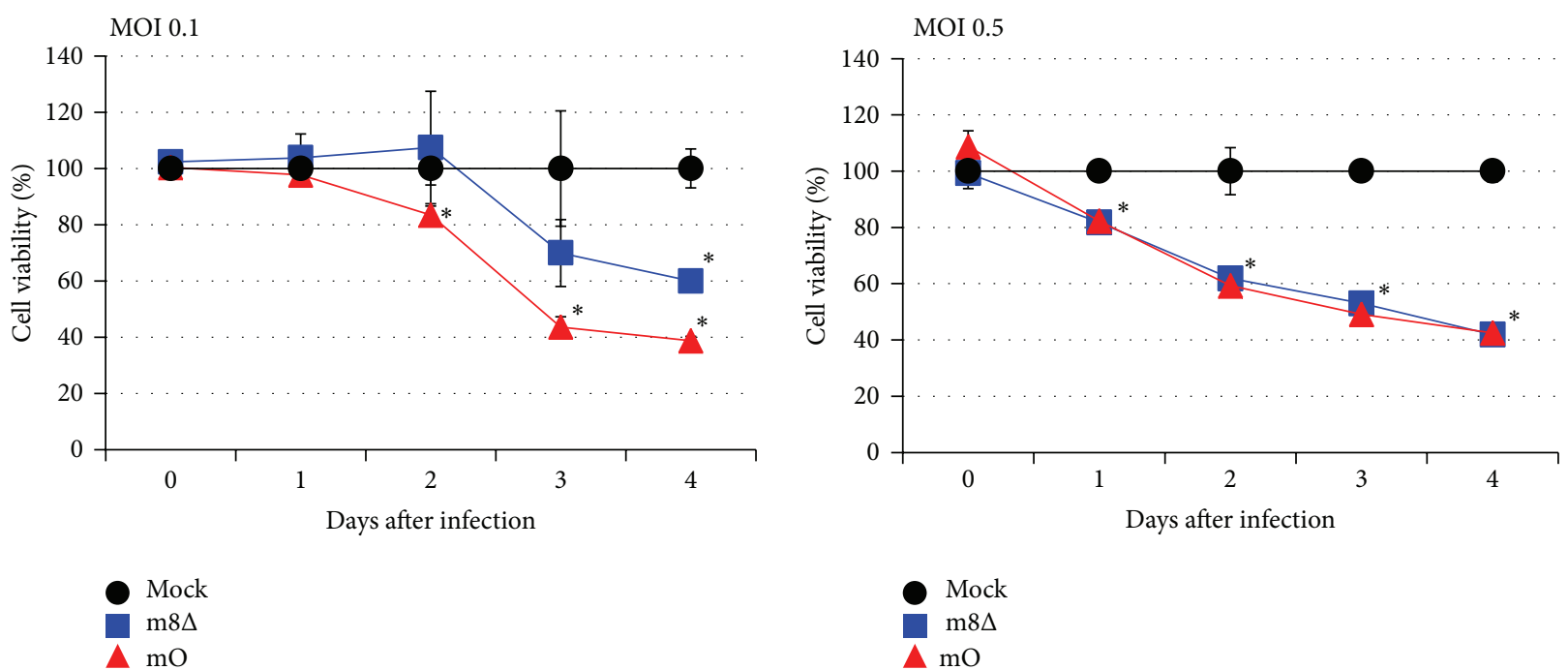

(a)

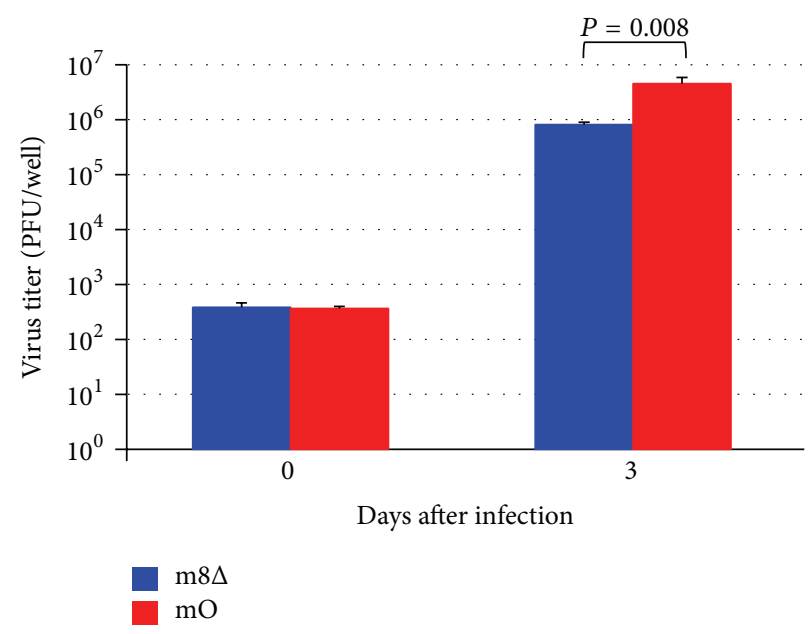

(b)

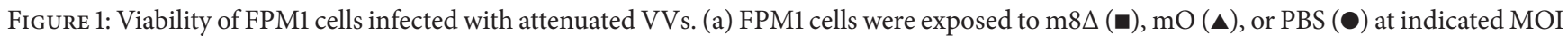
for $2 \mathrm{hrs}$. After extensive wash, the cells were cultured for indicated periods and the cell growth was assessed by using cell counting kit 8 . The cell viabilities are expressed as percentages of the cell survival of mock-infected cultures. The data are presented as mean \pm SD of triplicate wells. Asterisks indicate statistical significance $(P<0.05)$ compared to the mock-infected controls. (b) The proliferation of VVs in FPM1 cells infected with the virus at MOI 0.1 was determined by titrating the cell lysates collected at indicated days. The data are presented as mean \pm SD of triplicate wells. Statistical significance was determined as $P<0.05$. Similar results were obtained in two independent experiments.

eradication of virus-infected cells should not be eliminated by oncolytic viruses during treatment. Thus, it is important to confirm the resistance of CTLs to cytolysis by $\mathrm{m} 8 \Delta$. To assess the susceptibility of Tax-specific CTLs to killing by $\mathrm{m} 8 \Delta, 4 \mathrm{O} 1 / \mathrm{C} 8$ cells were stimulated with formalin-fixed FPM1 cells to induce cell proliferation and then were exposed to $m 8 \Delta$ at MOI 2. As shown in Figure 2(a), exposure of $401 / \mathrm{C} 8$ to $\mathrm{m} 8 \Delta$ did not influence the growth of the CTLs. In contrast, dramatic decrease in the viability of FPM1 was observed after infection of $\mathrm{m} 8 \Delta$ at MOI 2 (Figure 2(b)). The enhanced cytolysis of FPM1 should be due to higher amount of inoculated virus compared with that used in Figure 1. The assessment of virus titer in the virus-exposed 4O1/C8 demonstrated that the titer of 401/C8-associated virus was stable during the first 4 days, suggesting that $\mathrm{m} 8 \Delta$ was not able to proliferate in the CTLs but was stable for several days in the presence of the CTLs (Figure 2(c)). Alternatively, it is also possible that low levels of $\mathrm{m} 8 \Delta$ proliferation may compensate the natural reduction of the virus titer in the culture. These results indicated that 4O1/C8 is resistant to the cytolysis by $\mathrm{m} 8 \Delta$ and suggested that virotherapy using $\mathrm{m} 8 \Delta$ does not affect the function of CTLs. Thus, m $8 \Delta$ could be applicable for the combination therapies using oncolytic viruses and antigen-specific T cells against HTLV-I-infected cells.

3.3. Lack of IFN- $\gamma$ Production Was Correlated with the Resistance of FPM1V.EFGFP/8R Cells to Killing by 4O1/C8 $C T L$. We have previously established an assay system by which we can evaluate the susceptibility of HTLV-I-infected 

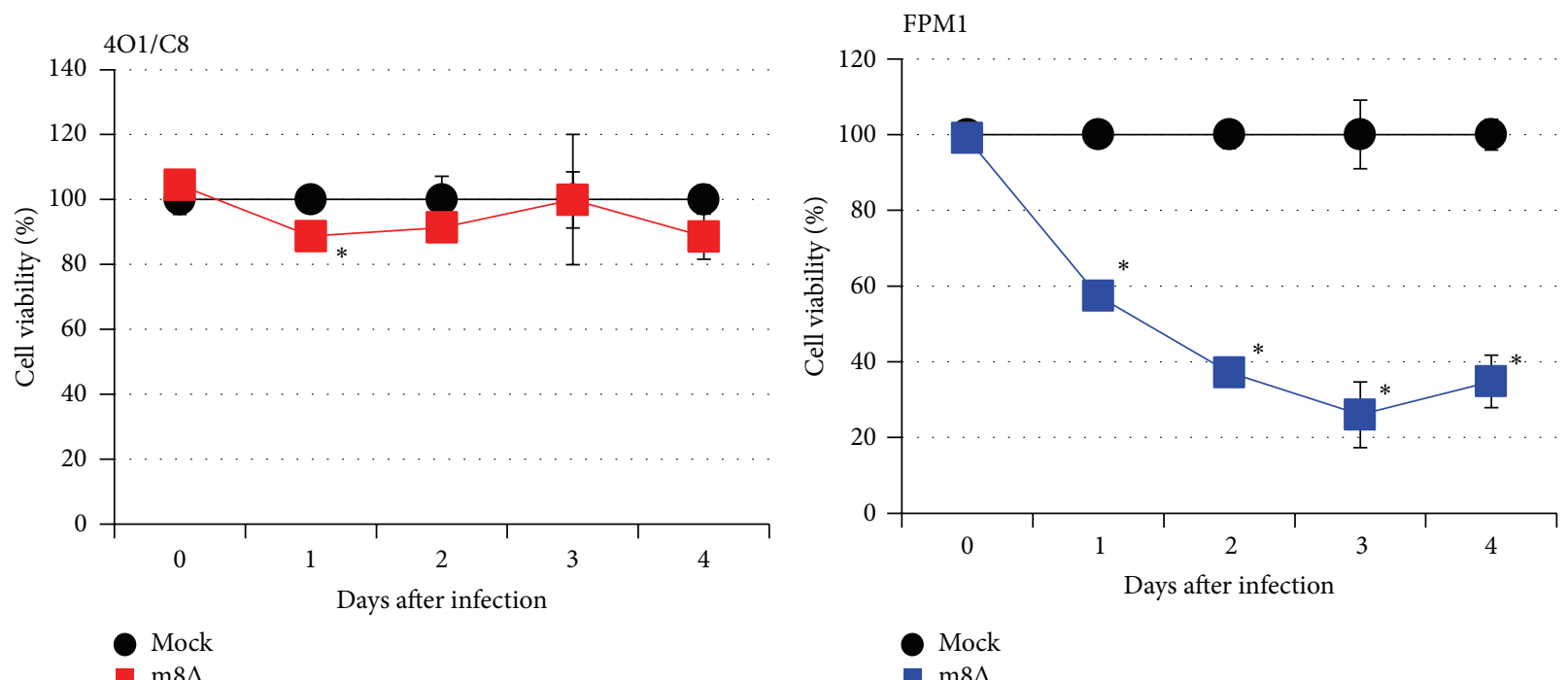

(a)

(b)

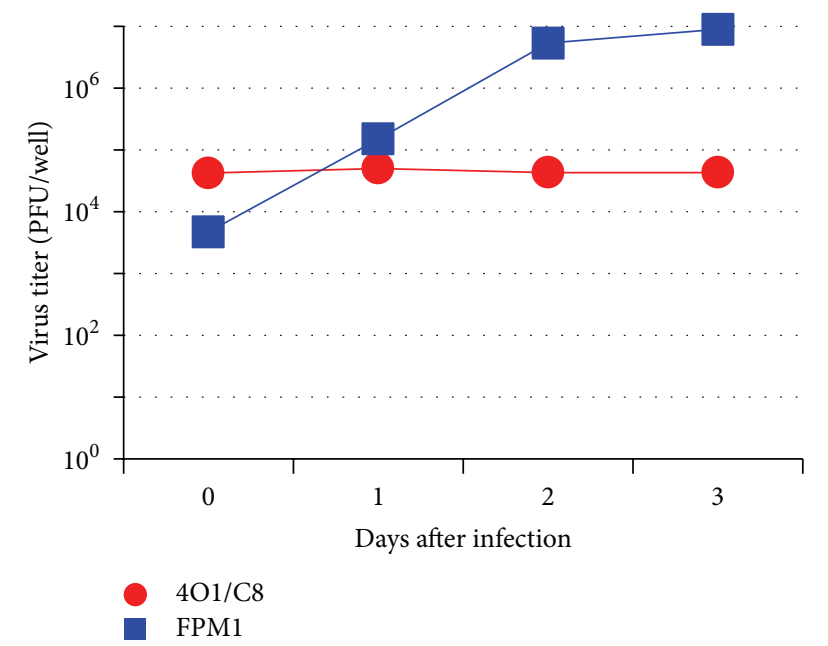

(c)

Figure 2: A Tax-specific CTL line, 4O1/C8, was resistant to killing by m8 4 . The 4O1/C8 (a) or FPM1 (b) cells were exposed to m8 $(\mathbf{\square})$ or PBS (•) at MOI 2 for $2 \mathrm{hrs}$. After extensive wash, the cells were cultured for indicated periods and the cell growth was assessed by using cell counting kit 8 . The cell viabilities are expressed as percentages of the cell survival of mock-infected cultures. The data are presented as mean \pm SD of triplicate wells. Asterisks indicate statistical significance $(P<0.05)$ compared to the mock-infected controls. Similar results were obtained in two independent experiments. (c) The proliferation of VVs in 4O1/C8 (•) or FPM1 (घ) cells infected with the virus at MOI 2 was determined by titrating the cell lysates collected at indicated days. The data are presented as mean of duplicate wells.

cells to CTL killing by flow-cytometric analysis [25]. In this study, we used EGFP-expressing subclones of FPM1 cells, FPM1V.EFGFP and FPM1V.EFGFP/8R, as target cells of Tax-specific CTLs. FPM1V.EFGFP/8R cells were previously isolated by continuously cocultivating with 4O1/C 8 cells and were shown to be resistant to killing by $401 / \mathrm{C} 8$ due to downregulation of MHC-I but not Tax expression [25]. As we have previously reported, mixed culture of FPM1V.EFGFP and 4O1/C8 cells resulted in the dramatic decrease of EGFPpositive FPM1V.EFGFP fractions (Figure 3(a)). In contrast, the percentage of FPM1V.EFGFP/8R increased in 4 days of mixed culture with $4 \mathrm{O} 1 / \mathrm{C} 8$ cells, indicating the resistance of FPM1V.EFGFP/8R to killing by $4 \mathrm{O} 1 / \mathrm{C} 8$. To determine whether the activation of $4 \mathrm{O} 1 / \mathrm{C} 8$ was induced in the mixed culture, IFN- $\gamma$ production in the supernatants was evaluated. As shown in Figure 3(b), mixed culture of 4O1/C8 cells with FPM1V.EFGFP induced IFN- $\gamma$ secretion whereas that with FPM1V.EFGFP/8R did not. Thus, production of IFN$\gamma$ in the mixed culture correlated with killing of the HTLVI-infected cells by $401 / \mathrm{C} 8$. We next infected the mixed culture of $4 \mathrm{O} 1 / \mathrm{C} 8$ and FPM1V.EFGFP/8R cells with $\mathrm{m} 8 \Delta$ to determine whether cytolysis of the CTL-resistant cells by the oncolytic virus induced the activation of the Taxspecific CTLs. As shown in Figure 3(a), slight decrease of GFP positive cell fraction $(7.4 \pm 0.2 \%)$ was observed in 4 days of mixed culture with $\mathrm{m} 8 \Delta$, which was in stark contrast to the apparent increase of GFP positive cell fraction in the absence of $\mathrm{m} 8 \Delta(22.4 \pm 0.3 \%)$, demonstrating that cytolysis 

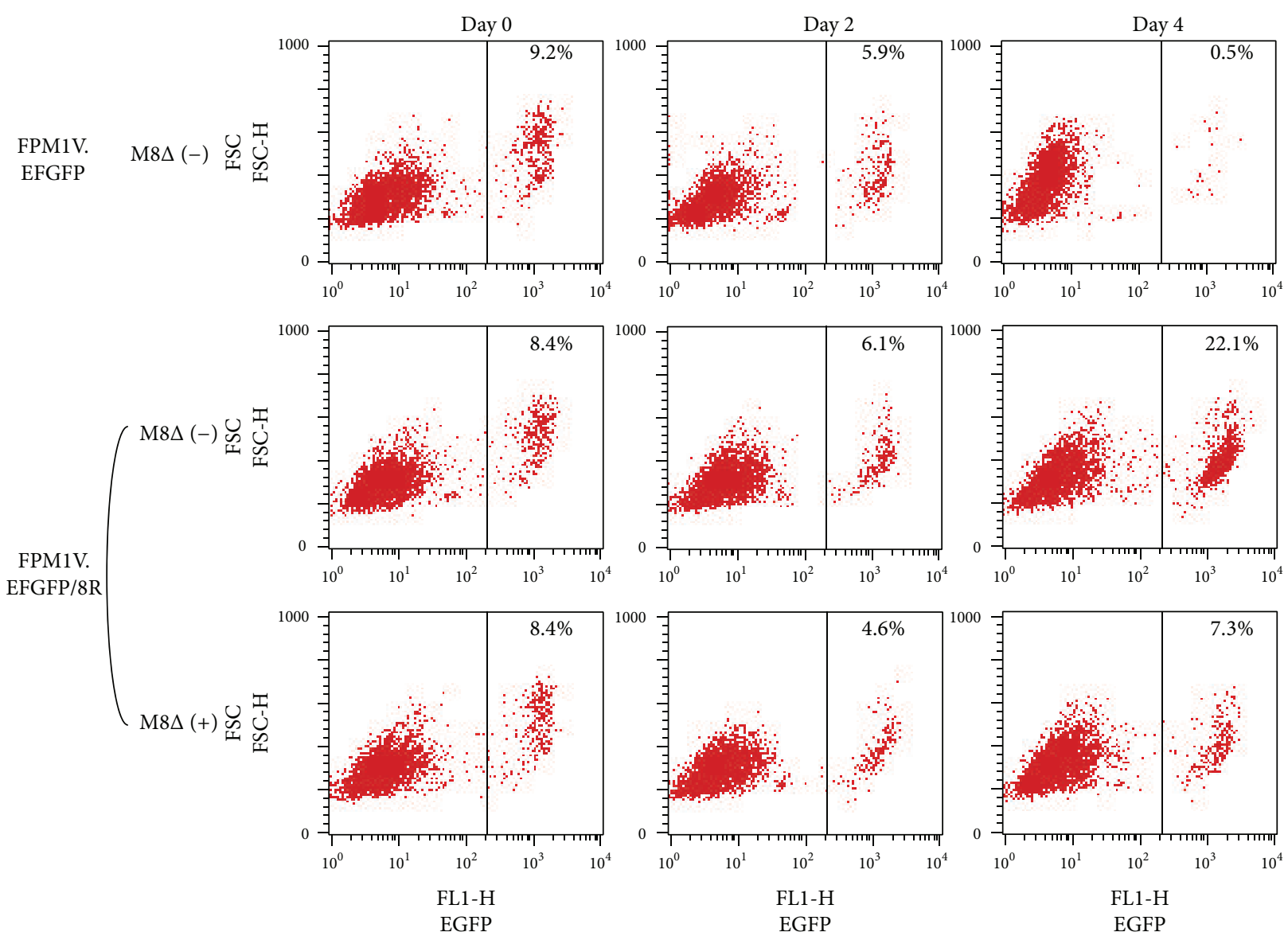

(a)

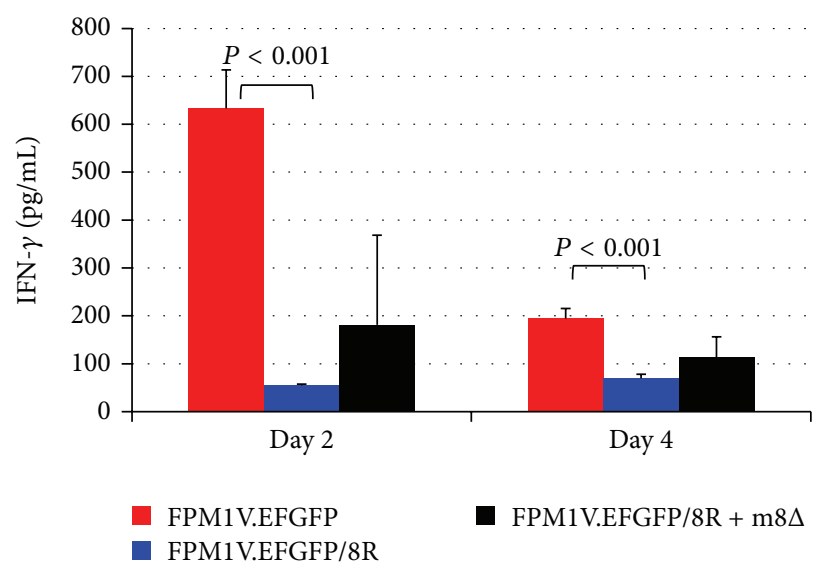

(b)

FIGURE 3: Lack of IFN- $\gamma$ production was correlated with the resistance of FPM1V.EFGFP/8R cells to killing by 4O1/C8. (a) FPM1V.EFGFP or FPM1V.EFGFP/8R cells $\left(5 \times 10^{4} /\right.$ well $)$ were mixed with $4 \mathrm{O} 1 / \mathrm{C} 8$ cells $\left(5 \times 10^{5} /\right.$ well $)$ at an $\mathrm{E}: \mathrm{T}$ ratio of $10: 1$ in the presence or absence of m $8 \Delta$ $\left(1 \times 10^{5} \mathrm{PFU} /\right.$ well $)$ and subjected to flow-cytometric analysis for the expression of EGFP at the indicated days. Percentage of EGFP positive cells is indicated in each panel. (b) Production of IFN- $\gamma$ in the supernatants of mixed culture prepared in (a) was measured by ELISA at the indicated days of culture. The data represent the mean \pm SD of triplicate wells. Statistical significance was determined as $P<0.001$. Similar results were obtained in two independent experiments. 
of FPM1V.EFGFP/8R was induced by $m 8 \Delta$. There were no cells surviving after extended cultivation of the virus-infected FPM1V.EFGFP/8R cells in the experiment (data not shown). However, IFN- $\gamma$ production was not detected in the mixed culture with $\mathrm{m} 8 \Delta$ (Figure 3(b)), indicating that cytolysis of the HTLV-I-infected cells by $\mathrm{m} 8 \Delta$ was independent of CTL activation.

3.4. Characterization of Recombinant VVs Expressing SCTs of Rat MHC-I. To improve the efficiency of oncolytic viruses, various types of modifications have been reported [17]. In this study, we have utilized SCTs with a Tax-epitope to enhance the oncolytic ability of m8 8 against HTLV-Iinfected cells in combination with Tax-specific CTLs. Tax180 epitope was previously identified as an RT1. $\mathrm{A}^{1}$-restricted CTL epitope recognized by a Tax-specific CTL line, 4O1/C8 [14]. As a negative control, we have chosen a putative RT1. $\mathrm{A}^{1}$ restricted epitope in the envelope of HIV-1 NL4-3 strain, NLEnv371, which was determined to have the same point as Tax180 epitope scored by epitope prediction data via http://www.syfpeithi.de/ [35]. A schematic representation of SCTs is shown in Figure 4(a). We have introduced the coding sequence of SCTs with Tax180 or NLEnv371 into the genome of $\mathrm{m} 8 \Delta$ and obtained $\mathrm{m} 8 \Delta /$ RT1AlSCTax180L or m8 $\Delta$ RT1AISCNLEnv371L, respectively. The SCT protein

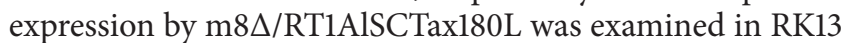
cells. Among the 4 clones tested, 2 clones (Numbers 7 and 8) appeared to express SCTs and clone Number 7 was used for further studies (Figure 4(b)). The expression of SCTs by m8 $\Delta$ /RT1AlSCNLEnv371L was also confirmed by Western blotting (Figure 4(c)). We further assessed the function of the SCTs expressed by m8 $\Delta$ /RT1AlSCTax180L, by infecting the virus to RK13 cells and coculturing the infected cells with 4O1/C8. As shown in Figure 4(d), RK13 cells infected with $\mathrm{m} 8 \Delta / \mathrm{RT} 1 \mathrm{AlSCTax} 180 \mathrm{~L}$ were able to induce IFN- $\gamma$ secretion by $4 \mathrm{O} 1 / \mathrm{C} 8$. In contrast, RK13 cells infected with m8 8 /RT1AlSCNLEnv371L induced little amount of IFN- $\gamma$ secretion by the Tax-specific CTLs. These results indicated that SCTs expressed by m8 $\Delta /$ RT1AlSCTax180L were able to activate Tax-specific CTLs. Thus, it is expected that m8 $8 /$ RT1AlSCTax180L possesses dual functions of both lysing HTLV-I-infected cells and activating Tax-specific CTLs.

3.5. Combined Effects of 4O1/C8 and $m 8 \Delta$ on Killing of CTL-Resistant HTLV-I-Infected Cells. To examine the combined effects of Tax-specific CTLs and $\mathrm{m} 8 \Delta$ expressing SCTs, we next infected FPM1V.EFGFP/8R cells with m8 8 RT1AlSCTax180L or m8 $/$ RT1AlSCNLEnv371L and cocultivated the infected cells with 4O1/C8. As shown in Figure 5, the proportion of FPM1V.EFGFP/8R cells in the mixed culture clearly decreased at 4 days after m8 8 /RT1AlSCNLEnv371L infection compared to the mockinfected controls. The decrease of FPM1V.EFGFP/8R cells was MOI-dependent and may be due to oncolytic ability of the virus, since IFN- $\gamma$ production was not detected in the mixed culture (Figure 6). A greater reduction of EGFP-positive cells was observed in the mixed culture of FPM1V.EFGFP/8R

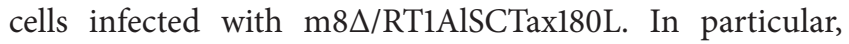

m8 8 /RT1AlSCTax180L infection at MOI 10 induced most dramatic elimination of FPMIV.EFGFP/8R cells. This may be due to the combined effects of oncolytic activity and activation of 4O1/C8 cells induced by SCTs with Tax presentation, since IFN- $\gamma$ production was clearly induced in the mixed culture (Figure 6). Induction of IFN- $\gamma$ was partly due to the direct effect of m8 $\Delta /$ RT1AlSCTax180L to $4 \mathrm{O} 1 / \mathrm{C} 8$, since direct exposure of $4 \mathrm{O} 1 / \mathrm{C} 8$ to m8 $8 /$ RT1AISCTax180L, but not to m8 8 /RT1AlSCNLEnv371L, resulted in the production of IFN- $\gamma$ (data not shown). We also examined the cytolytic activity of $\mathrm{m} 8 \Delta \mathrm{s}$ expressing SCTs in the absence of $4 \mathrm{O} 1 / \mathrm{C} 8$ to determine whether expression of different epitopes affects the lysis of FPM1V.EFGFP/8R cells. As shown in Figure 7(a), equivalent levels of cell growth inhibition were observed in FPM1V.EFGFP/8R cells infected with either m8 $\Delta$ /RT1AlSCTax180L or m8 $\Delta /$ RT1AlSCNLEnv371L. These results demonstrated that there is no difference in direct cytolytic ability between m8D/RT1AlSCTax180L and m8 8 /RT1AISCNLEnv371L and further indicated that significantly strong reduction of EGFP-positive cell fraction observed in the mixed culture of $4 \mathrm{O} 1 / \mathrm{C} 8$ and m8 8 /RT1AlsCTax180L-infected FPM1V.EFGFP/8R cells was due to the additional cytotoxic activity of 4O1/C8 activated by m8L/RT1AlSCTax180L-mediated epitope presentation. Finally, we have evaluated the virus titers in FPM1V.EFGFP/8R cells infected with VVs in the presence or absence of 4O1/C8 cells to determine whether the CTLs influence the replication of VVs. As shown in Figure 7(b), we have not observed any significant differences of the virus titer between VV-infected FPM1V.EFGFP/8R cells cultivated with 4O1/C8 and those without 4O1/C8 during the first 4 days after infection regardless of the VVs used, although slight reduction of VV titer was induced by the addition of $4 \mathrm{O} 1 / \mathrm{C} 8$ cells in most of the samples examined. Thus, the CTLs did not significantly affect the replication of VVs in the present experiments.

\section{Discussion}

The primary effect of oncolytic virotherapy depends on the vigorous viral replication and spread within tumor tissues. In addition, it has been reported that oncolytic virus-mediated tumor destruction leads to the activation of tumor-specific immune responses and the improved efficacy of virotherapy $[36,37]$. Thus, activation of tumor-specific immune responses could be another strategy to enhance tumor specific killing by attenuated oncolytic viruses. Indeed, GM-CSF-encoding $\mathrm{VV}$ or herpes virus has been developed to effectively induce tumor regression $[38,39]$. Encoding a tumor antigen within an oncolytic virus also enhanced the tumor-specific immune responses and the efficacy of tumor eradication [40, 41]. Based on these previous reports, we have developed a novel combination therapy against HTLV-I tumor in a rat model system, which consists of a Tax-specific CTL line and an attenuated VV expressing SCTs with a Tax-epitope. In line with the previous reports, our present results demonstrated the effective cytolysis of HTLV-I-infected cells by an attenuated VV and the synergistic effects between activated virusspecific $\mathrm{T}$ cells and oncolytic viruses toward eliminating 


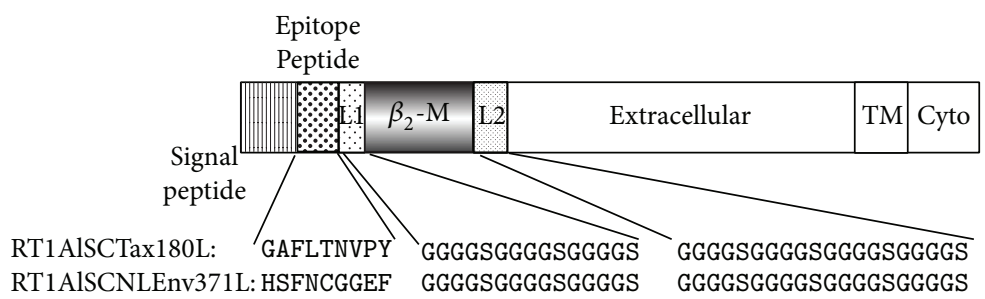

(a)

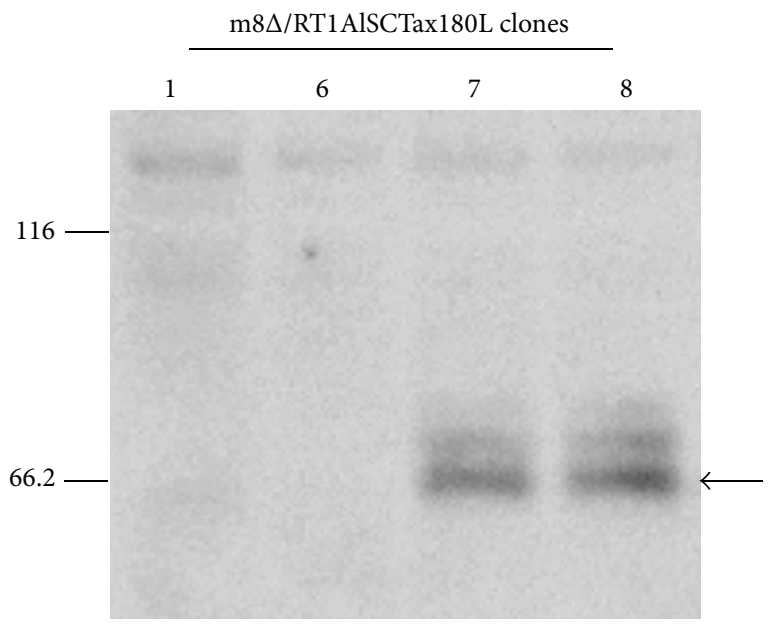

(b)

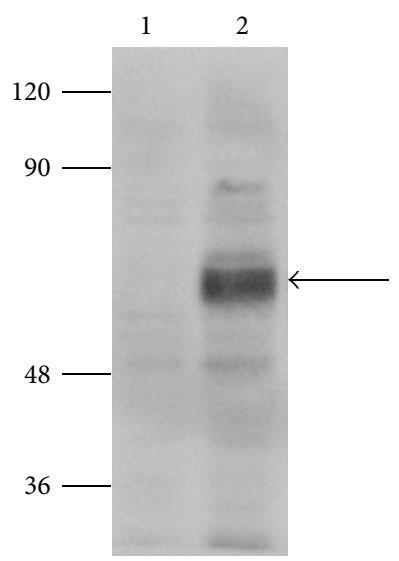

(c)

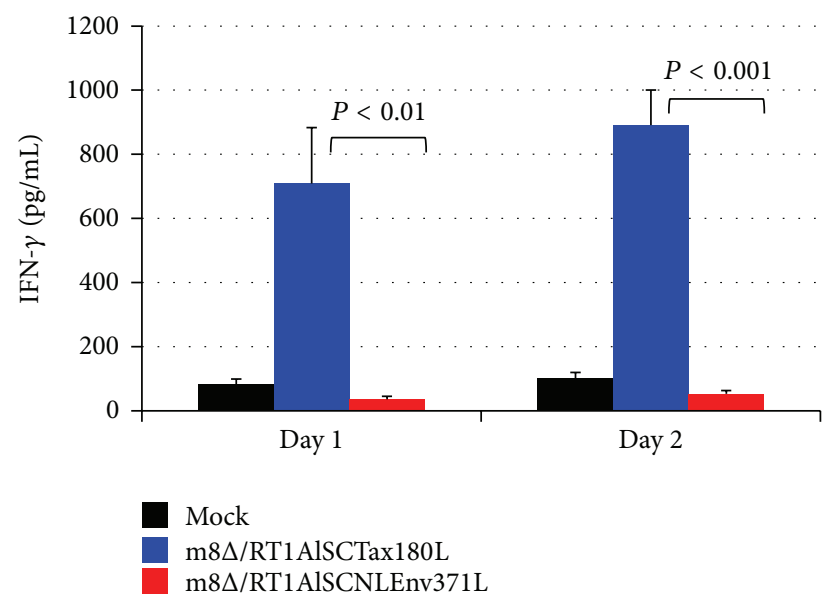

(d)

FIGURE 4: Characterization of m8 $\Delta$ expressing SCTs. (a) Diagram of SCTs encoding Tax180-188 or NLEnv371-379 linked to $\beta_{2} \mathrm{~m}$ and RT1.A ${ }^{1}$ molecules with two linkers. L1, linker 1; L2, linker 2; TM, transmembrane region; Cyto, cytoplasmic region. ((b) and (c)) Whole cell extracts were isolated from RK13 cells infected with indicated clones of m8 8 RT1AlSCTax180L (b) or RK13 cells infected with m8 (lane 1) or m8 $\Delta$ /RT1A1SCNLEnv371L (lane 2) (c) and $50 \mu \mathrm{g}$ of each lysate was subjected to Western blotting analysis for the expression of the SCT of MHC-I proteins. Arrows indicate the SCT of MHC-I proteins detected by an anti-rat MHC-I antibody. Molecular weight markers are indicated $(\mathrm{kDa})$ on the left margin. (d) RK13 cells were exposed to m8 8 /RT1AlSCTax180L, m8 $\Delta /$ RT1AlSCNLEnv371L, or PBS for 2 hrs. After extensive wash, the cells were cocultivated with 4O1/C8 for indicated days. Production of IFN- $\gamma$ in the supernatants was measured by ELISA. The data represent the mean \pm the SD of triplicate wells. Statistical significance was determined as $P<0.01$. Similar results were obtained in two independent experiments.

tumor cells. Introduction of SCT system should be extremely important in the case of HTLV-I infection, because repression of Tax expression is frequently observed in HTLV-I carriers and is a possible cause of the declined virus-specific immune responses [8]. By using SCTs, effective presentation of Taxepitopes could be expected to induce proper activation of
anti-HTLV-I T cell responses, even when Tax expression is repressed. Since repression of antigen presentation by MHCI represents a common feature of tumor cells and is one of the mechanisms of tumor immune evasion, encoding a SCT of MHC-I gene within an attenuated oncolytic virus could also be effective against a broad range of tumors. Moreover, 


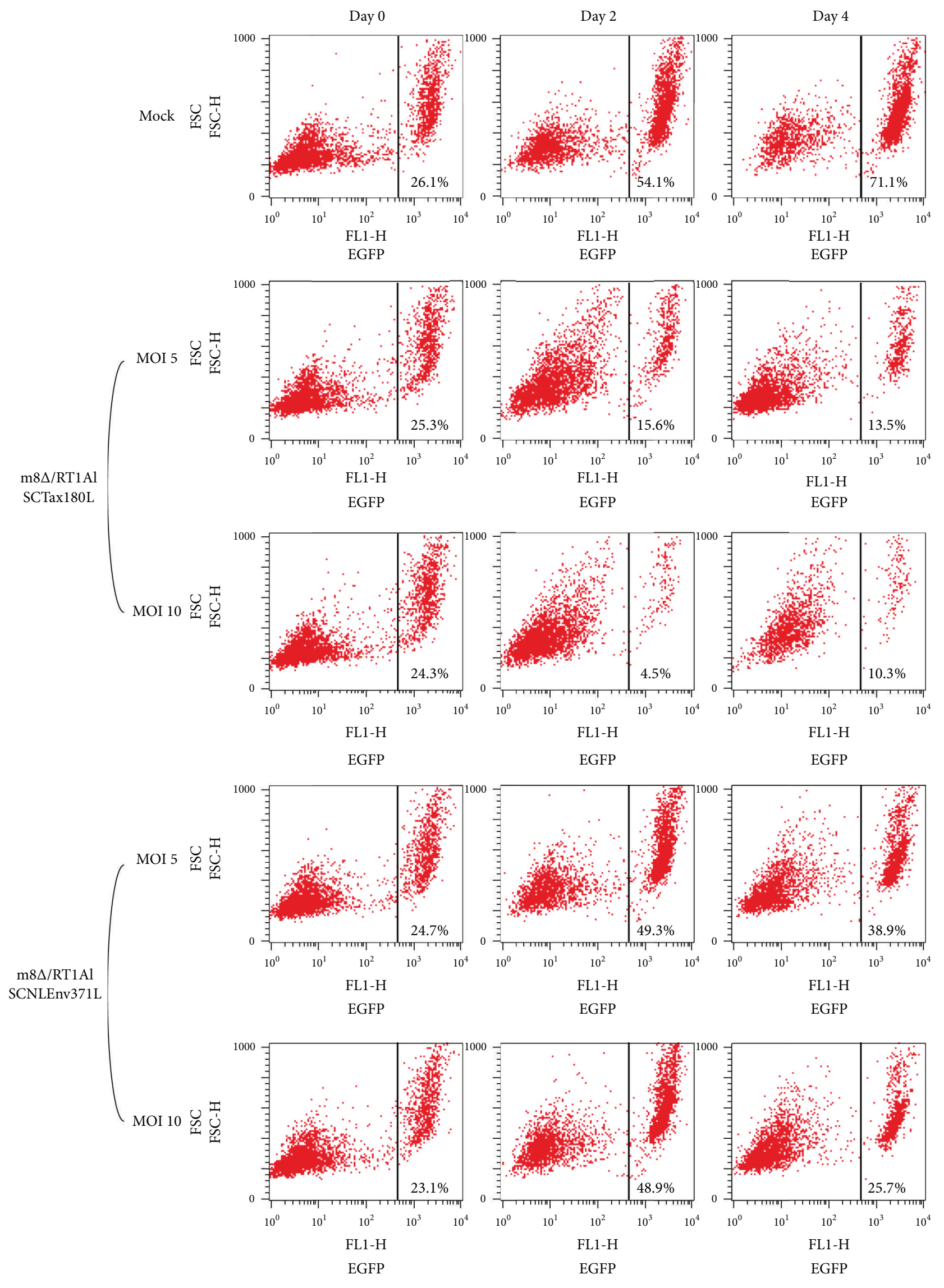

(a)

Figure 5: Continued. 


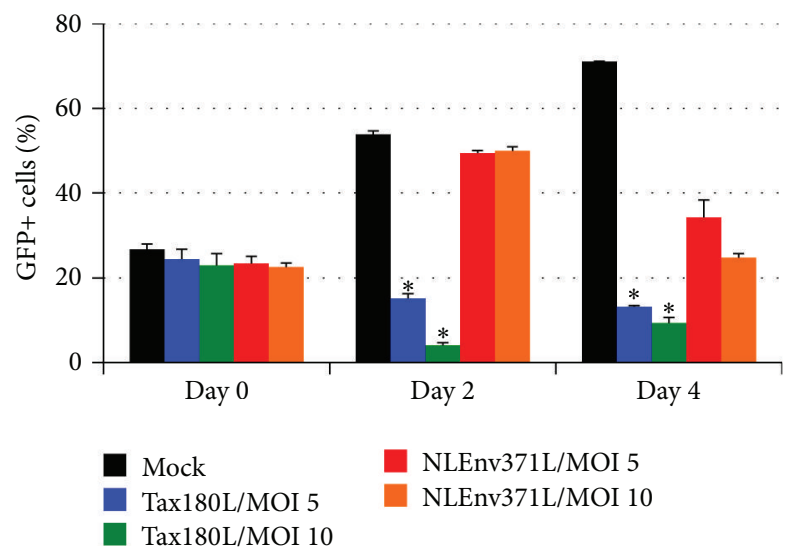

(b)

FIGURE 5: Combined effects of 4O1/C8 and m8 on killing of CTL-resistant HTLV-I-infected cells. (a) FPM1V.EFGFP/8R cells were exposed to $\mathrm{m} 8 \Delta$ /RT1AlSCTax180L, m8 8 /RT1AlSCNLEnv371L, or PBS for $2 \mathrm{hrs}$ at indicated MOI. After extensive wash, the cells were cocultivated with 4O1/C8 for indicated periods and subjected to flow-cytometric analysis for the expression of EGFP at the indicated days. Percentage of EGFP positive cells is indicated in each panel. (b) Bar graph of the flow-cytometric data. The data are presented as mean \pm SD of triplicate wells. Asterisks indicate statistical significance $(P<0.01)$ compared to the m8 $\Delta /$ RT1AlSCNLEnv371L-infected cells with corresponding MOI.

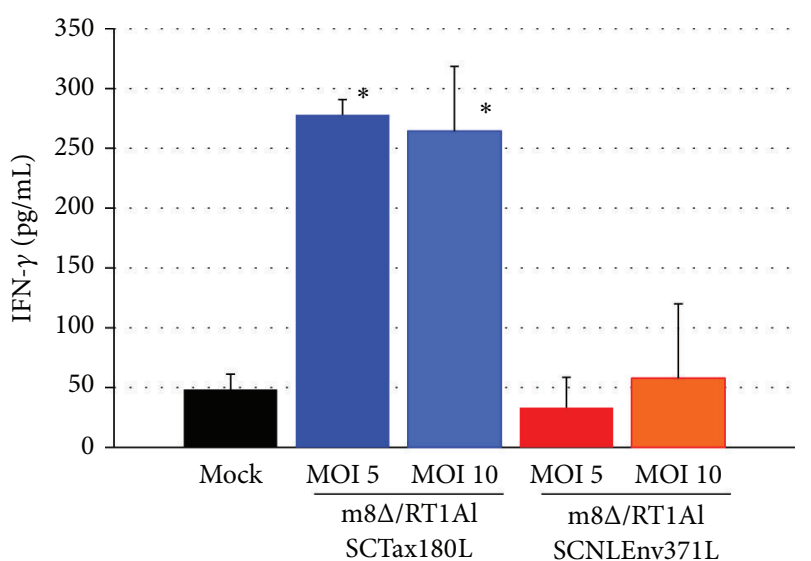

FIGURE 6: Production of IFN- $\gamma$ by $4 \mathrm{O} 1 / \mathrm{C} 8$ that was cocultured with recombinant m8 $\Delta$-exposed FPM1V.EFGFP/8R cells. FPM1V.EFGFP/8R cells were exposed to m8 $\Delta / \mathrm{RT} 1 \mathrm{AlSCTax} 180 \mathrm{~L}$, m8 $\Delta /$ RT1AISCNLEnv371L, or PBS for $2 \mathrm{hrs}$ at indicated MOI. After extensive wash, the cells were cocultivated with 4O1/C8 for 2 days. Production of IFN- $\gamma$ in the supernatants of mixed culture was measured by ELISA. The data represent the mean \pm SD of triplicate wells. Asterisks indicate statistical significance $(P<0.05)$ compared to the mock-infected controls.

it has been reported that combining adoptive cell therapy with oncolytic viruses leads to effective elimination of tumor cells [42]. In addition to the primary effects of direct killing of tumor cells, tumor-specific $\mathrm{T}$ cells were also known to enhance oncolysis in vivo by carrying oncolytic viruses to distal tumor sites [43]. Thus, combined administration of SCTexpressing oncolytic virus and tumor-specific T cells could be one of the ideal combinations to maximize antitumor effects. However, it is also important to note that CTLs may possibly have inhibitory effects on the replication of oncolytic viruses. Although significant inhibition of the virus replication was not induced by 4O1/C8 cells as shown in Figure 7(b), IFN- $\gamma$ produced by the CTLs could have the potential to exert adverse effects on the virus replication in different conditions. Thus, it should be important to consider the effects of CTLs on virus replication and oncolytic activity when we design the combination therapy of antigen-expressing oncolytic viruses and tumor-specific T cells.

VVs are known to have unique biological properties, including resistance to antibody- and compliment-mediated neutralization abilities in blood [44, 45]. Taking advantage of the properties, a recent clinical trial has successfully demonstrated the intravenous delivery and replication of oncolytic VVs in metastasized tumor tissue [21]. Since HTLVI primarily infects $\mathrm{T}$ cells in the blood and expands through the bloodstream, it is reasonable to assume that VVs could also reach systemically spreading HTLV-I-infected cells after intravenous administration. In addition, the unique biological nature of VVs made them possible to spread systemically even in patients with a history of live VV vaccination [21]. Thus, it is anticipated that oncolytic VVs could be effective in HTLV-I-infected individuals with anti-VV immunity.

The efficacy of a cancer treatment has to be balanced against its potential toxicity to normal cells. The safety of m $8 \Delta$ has been demonstrated through the use of its natural counterpart, $\mathrm{m} 8$, for smallpox vaccine [23]. It is of note that $m 8 \Delta$ infection showed neither viral replication in nor cytolysis of Tax-specific CTLs (Figure 2), further indicating the reduced toxicity to normal cells. However, due to the lack of $B 5 R$ gene, oncolytic activity of $m 8 \Delta$ was shown to be declined [24]. Our present observation also confirmed the weaker oncolytic activity of $\mathrm{m} 8 \Delta$ than that of $\mathrm{mO}$ in a rat HTLV-I-infected cell line (Figure 1). In addition, we observed the lack of Tax-specific $\mathrm{T}$ cell activation in the mixed culture of FPM1V.EFGFP/8R cells infected with $\mathrm{m} 8 \Delta$ (Figure 3) or m8 $\Delta /$ RT1AlSCNLEnv371L (Figure 6). Since FPM1V.EFGFP/8R cells are known to express Tax protein [25], it is anticipated that cytolysis of FPM1V.EFGFP/8R by $\mathrm{m} 8 \Delta$ should lead to the release of the viral antigen and 


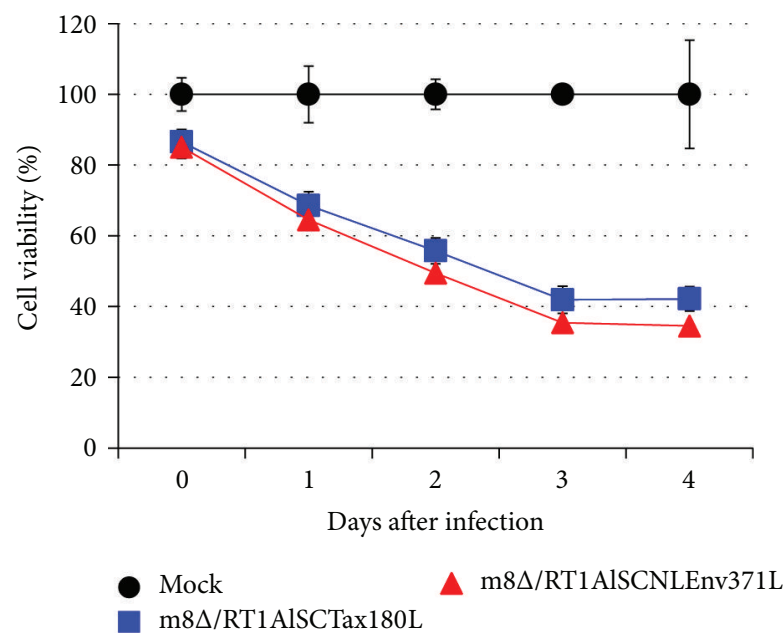

(a)

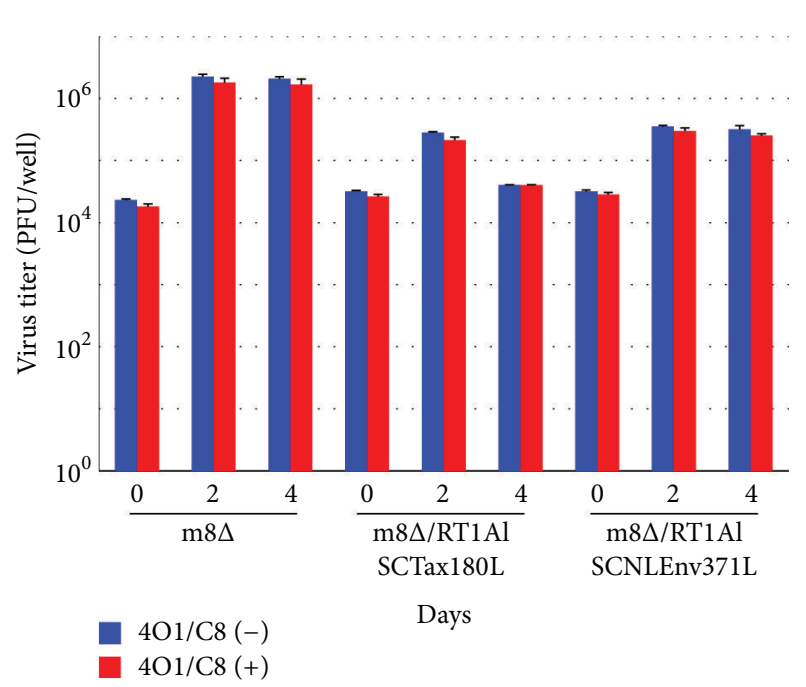

(b)

FIGURE 7: Viability of and viral replication in FPM1V.EFGFP/8R cells exposed to recombinant m8 $\Delta$ s. (a) FPM1V.EFGFP/8R cells were exposed

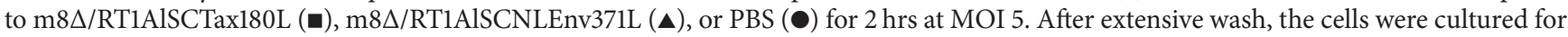
indicated periods and the cell growth was assessed by using cell counting kit 8 . The cell viabilities are expressed as percentages of the cell survival of mock-infected cultures. The data are presented as mean \pm SD of triplicate wells. (b) FPM1V.EFGFP/8R cells $\left(5 \times 10^{4} /\right.$ well) were exposed to $\mathrm{m} 8 \Delta$ at MOI 2, or m8 $\mathrm{R}$ RT1AlSCTax180L, or m8 8 RT1AlSCNLEnv371L at MOI 5. After extensive wash, the cells were cultured in the presence or absence of $4 \mathrm{O} 1 \mathrm{C} 8$ cells $\left(2.5 \times 10^{5} /\right.$ well $)$ for indicated periods and were collected for the evaluation of virus proliferation. The proliferation of VVs was determined by titrating the cell lysates. The data are presented as mean \pm SD of triplicate wells.

the activation of 4O1/C8 cells. Indeed, our previous results showed that addition of Tax180 peptide directly to the culture led to the activation of 4O1/C8 [25]. Thus, it is possible that cytolysis of FPM1V.EFGFP/8R cells by $\mathrm{m} 8 \Delta$ was slowly processed even when $\mathrm{m} 8 \Delta$ efficiently replicated in the cells and that the amount of Tax protein released from destructed cells was not enough to activate Tax-specific CTLs in the present experimental condition. Under this condition, to compensate the reduced oncolytic ability of $m 8 \Delta$, we introduced a gene encoding SCT with Tax180 within the genome of $\mathrm{m} 8 \Delta$ and showed the improved cytolysis of FPM1 cells by Tax-specific CTLs without altering direct oncolytic ability of $\mathrm{m} 8 \Delta$. It seemed that the ability to induce $\mathrm{T}$ cell activation

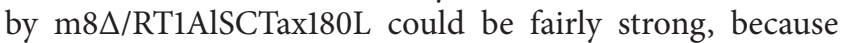
rabbit RK13 cells also became capable of inducing IFN$\gamma$ production by $4 \mathrm{O} 1 / \mathrm{C} 8$ cells after m8 8 /RT1AlSCTax180L infection (Figure 4(d)). Since uncontrolled activation of $\mathrm{T}$ cells may result in normal cell injury, it is also necessary to carefully evaluate the safety of the virus in vivo. In addition, there are other strategies to overcome the reduced oncolytic activity of attenuated viruses [17]. As for m8 8 , Hikichi et al. have successfully developed a microRNA-regulated system, by which $m 8 \Delta$ can selectively express B5R in tumor cells and demonstrated full restoration of its oncolytic activity [24]. These strategies could be also combined to further enhance oncolytic activities without damaging normal cells.

ATL is known to acquire resistance to conventional chemotherapy and has a poor prognosis. Although alloHSCT had been developed for the treatment of ATL, patients who are eligible for the treatment are still limited [46, 47]. Recently, a novel promising therapy using a humanized anti-CCR4 monoclonal antibody has been reported to be effective against ATL [48]. In addition, there are other novel target proteins discovered for T cell therapies against ATL, including NY-ESO-1 [49], and hTERT [50]. Since the VV encoding SCTs developed in this study as well as previously reported VSV [19] have unique mechanisms of action against HTLV-I-infected cells, it is possible that combination of these oncolytic viruses with the recently developed immune therapies could further enhance the efficacy of ATL treatment.

\section{Conclusion}

We demonstrated that an attenuated $\mathrm{VV}, \mathrm{m} 8 \Delta$, possesses oncolytic activity to HTLV-I-infected cells and that m8 encoding SCT with a Tax-epitope enhances the cytolysis of CTL-resistant HTLV-I-infected cells in combination with Tax-specific CTLs. This newly established VV expressing SCT should have combining tumor debulking activity of direct tumor lysis and activation of tumor specific CTLs. The combination of epitope specific-CTLs and attenuated VVs encoding SCTs with corresponding epitopes could be effective tool to eradicate tumors escaping from immune surveillance.
Abbreviations
ATL: $\quad$ Adult $\mathrm{T}$ cell leukemia
allo-HSCT: Allogeneic hematopoietic stem cell
$\beta_{2} \mathrm{~m}: \quad \beta_{2}$-microgrobulin
CTL: $\quad$ Cytotoxic T lymphocyte
HIV-1: Human immunodeficiency virus type 1 
HTLV-I: Human T cell leukemia virus type I

HAM/TSP: HTLV-I-associated myelopathy/tropical spastic paraparesis

MOI: Multiplicity of infection

MHC-I: Major histocompatibility complex class I

SCT: $\quad$ Single chain trimer

VV: $\quad$ Vaccinia virus

VSV: Vesicular stomatitis virus.

\section{Conflict of Interests}

The authors declare that there is no conflict of interests regarding the publication of this paper.

\section{Acknowledgments}

The authors thank Akiko Hirano, Yuriko Ishida, and Reiko Narita for technical assistance. This work was supported in part by grants from the Ministry of Education, Science, Culture, and Sports of Japan.

\section{References}

[1] Y. Hinuma, K. Nagata, and M. Hanaoka, "Adult T-cell leukemia: antigen in an ATL cell line and detection of antibodies to the antigen in human sera," Proceedings of the National Academy of Sciences of the United States of America, vol. 78, no. 10, pp. 64766480, 1981.

[2] B. J. Poiesz, F. W. Ruscetti, and A. F. Gazdar, "Detection and isolation of type $\mathrm{C}$ retrovirus particles from fresh and cultured lymphocytes of a patient with cutaneous T-cell lymphoma," Proceedings of the National Academy of Sciences of the United States of America, vol. 77, no. 12, pp. 7415-7419, 1980.

[3] A. Gessain, F. Barin, and J. C. Vernant, "Antibodies to human T-lymphotropic virus type-I in patients with tropical spastic paraparesis," The Lancet, vol. 2, no. 8452, pp. 407-410, 1985.

[4] M. Osame, K. Usuku, and S. Izumo, "HTLV-I associated myelopathy, a new clinical entity," The Lancet, vol. 1, no. 8488, pp. 1031-1032, 1986.

[5] M. Seiki, A. Hikikoshi, T. Taniguchi, and M. Yoshida, "Expression of the pX gene of HTLV-I: general splicing mechanism in the HTLV family," Science, vol. 228, no. 4707, pp. 1532-1534, 1985.

[6] M. Yoshida, "Multiple viral strategies of HTLV-1 for dysregulation of cell growth control," Annual Review of Immunology, vol. 19, pp. 475-496, 2001.

[7] S. Jacobson, H. Shida, D. E. McFarlin, A. S. Fauci, and S. Koenig, "Circulating CD8+ cytotoxic T lymphocytes specific for HTLVI pX in patients with HTLV-I associated neurological disease," Nature, vol. 348, no. 6298, pp. 245-248, 1990.

[8] M. Kannagi, A. Hasegawa, A. Takamori, S. Kinpara, and A. Utsunomiya, "The roles of acquired and innate immunity in human T-cell leukemia virus type 1-mediated diseases," Frontiers in Microbiology, vol. 3, Article ID 323, 2012.

[9] M. Kannagi, S. Matsushita, and S. Harada, "Expression of the target antigen for cytotoxic T lymphocytes on adult T-cellleukemia cells," International Journal of Cancer, vol. 54, no. 4, pp. 582-588, 1993.
[10] A. Hasegawa, T. Ohashi, S. Hanabuchi et al., "Expansion of human T-cell leukemia virus type 1 (HTLV-1) reservoir in orally infected rats: inverse correlation with HTLV-1-specific cellular immune response," Journal of Virology, vol. 77, no. 5, pp. 29562963, 2003.

[11] N. Kawano, K. Shimoda, F. Ishikawa et al., "Adult T-cell leukemia development from a human T-cell leukemia virus type I carrier after a living-donor liver transplantation," Transplantation, vol. 82, no. 6, pp. 840-843, 2006.

[12] N. Harashima, K. Kurihara, A. Utsunomiya et al., "Graft-versus-tax response in adult T-cell leukemia patients after hematopoietic stem cell transplantation," Cancer Research, vol. 64, no. 1, pp. 391-399, 2004.

[13] T. Ohashi, S. Hanabuchi, H. Kato et al., "Prevention of adult Tcell leukemia-like lymphoproliferative disease in rats by adoptively transferred T cells from a donor immunized with human T-cell leukemia virus type 1 Tax-coding DNA vaccine," Journal of Virology, vol. 74, no. 20, pp. 9610-9616, 2000.

[14] S. Hanabuchi, T. Ohashi, Y. Koya et al., "Regression of human T-cell leukemia virus type I (HTLV-I)-associated lymphomas in a rat model: peptide-induced T-cell immunity," Journal of the National Cancer Institute, vol. 93, no. 23, pp. 1775-1783, 2001.

[15] A. Masaki, T. Ishida, S. Suzuki et al., "Autologous Tax-specific CTL therapy in a primary adult T cell leukemia/lymphoma cellbearing NOD/Shi-scid, IL-2R $\gamma$ null mouse model," Journal of Immunology, vol. 191, no. 1, pp. 135-144, 2013.

[16] M. R. Junttila and F. J. de Sauvage, "Influence of tumour microenvironment heterogeneity on therapeutic response," Nature, vol. 501, no. 7467, pp. 346-354, 2013.

[17] S. J. Russell, K. W. Peng, and J. C. Bell, "Oncolytic virotherapy," Nature Biotechnology, vol. 30, no. 7, pp. 658-670, 2012.

[18] C. J. Breitbach, J. M. Paterson, C. G. Lemay et al., "Targeted inflammation during oncolytic virus therapy severely compromises tumor blood flow," Molecular Therapy, vol. 15, no. 9, pp. 16861693, 2007.

[19] R. Césaire, S. Olière, E. Sharif-Askari et al., "Oncolytic activity of vesicular stomatitis virus in primary adult T-cell leukemia," Oncogene, vol. 25, no. 3, pp. 349-358, 2006.

[20] P. H. Verardi, A. Titong, and C. J. Hagen, "A vaccinia virus renaissance: new vaccine and immunotherapeutic uses after smallpox eradication," Human Vaccines \& Immunotherapeutics, vol. 8, no. 7, pp. 961-970, 2012.

[21] C. J. Breitbach, J. Burke, D. Jonker et al., "Intravenous delivery of a multi-mechanistic cancer-targeted oncolytic poxvirus in humans," Nature, vol. 477, no. 7362, pp. 99-104, 2011.

[22] M. Kidokoro, M. Tashiro, and H. Shida, "Genetically stable and fully effective smallpox vaccine strain constructed from highly attenuated vaccinia LC16m8," Proceedings of the National Academy of Sciences of the United States of America, vol. 102, no. 11, pp. 4152-4157, 2005.

[23] T. Saito, T. Fujii, Y. Kanatani et al., "Clinical and immunological response to attenuated tissue-cultured smallpox vaccine LC16m8," Journal of the American Medical Association, vol. 301, no. 10, pp. 1025-1033, 2009.

[24] M. Hikichi, M. Kidokoro, T. Haraguchi et al., "MicroRNA regulation of glycoprotein B5R in oncolytic vaccinia virus reduces viral pathogenicity without impairing its antitumor efficacy," Molecular Therapy, vol. 19, no. 6, pp. 1107-1115, 2011.

[25] T. Ohashi, S. Hanabuchi, R. Suzuki, H. Kato, T. Masuda, and M. Kannagi, "Correlation of major histocompatibility complex class I downregulation with resistance of human T-cell leukemia 
virus type 1-infected T cells to cytotoxic T-lymphocyte killing in a rat model," Journal of Virology, vol. 76, no. 14, pp. 7010-7019, 2002.

[26] Y. Y. Yu, N. Netuschil, L. Lybarger, J. M. Connolly, and T. H. Hansen, "Cutting edge: single-chain trimers of MHC class I molecules form stable structures that potently stimulate antigen-specific T cells and B cells," Journal of Immunology, vol. 168, no. 7, pp. 3145-3149, 2002.

[27] T. F. Greten, F. Korangy, G. Neumann et al., "Peptide- $\beta 2$-microglobulin-MHC fusion molecules bind antigen-specific T cells and can be used for multivalent MHC-Ig complexes," Journal of Immunological Methods, vol. 271, no. 1-2, pp. 125-135, 2002.

[28] T. H. Kang, C. P. Mao, V. La, A. Chen, C. F. Hung, and T. C. Wu, "Innovative DNA vaccine to break immune tolerance against tumor self-antigen," Human Gene Therapy, vol. 24, no. 2, pp. 181-188, 2013.

[29] T. Ohashi, M. Nagai, H. Okada, R. Takayanagi, and H. Shida, "Activation and detection of HTLV-I Tax-specific CTLs by Epitope expressing Single-Chain Trimers of MHC Class I in a rat model," Retrovirology, vol. 5, p. 90, 2008.

[30] Y. Koya, T. Ohashi, H. Kato et al., "Establishment of a seronegative human T-cell leukemia virus type 1 (HTLV-1) carrier state in rats inoculated with a syngeneic HTLV-1- immortalized Tcell line preferentially expressing tax," Journal of Virology, vol. 73, no. 8, pp. 6436-6443, 1999.

[31] H. Amano, S. Morikawa, H. Shimizu et al., "Identification of the canarypox virus thymidine kinase gene and insertion of foreign genes," Virology, vol. 256, no. 2, pp. 280-290, 1999.

[32] H. Suzuki, M. Kidokoro, I. B. Fofana et al., "Immunogenicity of newly constructed attenuated vaccinia strain LC16m8 8 that expresses SIV Gag protein," Vaccine, vol. 27, no. 7, pp. 966-971, 2009.

[33] X. Zhang, T. Sobue, M. Isshiki et al., "Elicitation of both anti HIV-1 Env humoral and cellular immunities by replicating vaccinia prime Sendai virus boost regimen and boosting by CD40Lm," PLoS ONE, vol. 7, no. 12, Article ID e51633, 2012.

[34] H. Sato, C. Jing, M. Isshiki et al., "Immunogenicity and safety of the vaccinia virus $\mathrm{LC} 16 \mathrm{~m} 8 \triangle$ vector expressing SIV Gag under a strong or moderate promoter in a recombinant BCG primerecombinant vaccinia virus boost protocol," Vaccine, vol. 31, no. 35, pp. 3549-3557, 2013.

[35] H. Rammensee, J. Bachmann, N. P. N. Emmerich, O. A. Bachor, and S. Stevanović, "SYFPEITHI: database for MHC ligands and peptide motifs," Immunogenetics, vol. 50, no. 3-4, pp. 213-219, 1999.

[36] J. D. Naik, C. J. Twelves, P. J. Selby, R. G. Vile, and J. D. Chester, "Immune recruitment and therapeutic synergy: keys to optimizing oncolytic viral therapy?" Clinical Cancer Research, vol. 17, no. 13, pp. 4214-4224, 2011.

[37] A. Melcher, K. Parato, C. M. Rooney, and J. C. Bell, “Thunder and lightning: immunotherapy and oncolytic viruses collide," Molecular Therapy, vol. 19, no. 6, pp. 1008-1016, 2011.

[38] M. J. Mastrangelo, H. C. Maguire Jr., L. C. Eisenlohr et al., "Intratumoral recombinant GM-CSF-encoding virus as gene therapy in patients with cutaneous melanoma," Cancer Gene Ther$a p y$, vol. 6, no. 5, pp. 409-422, 1999.

[39] N. N. Senzer, H. L. Kaufman, T. Amatruda et al., "Phase II clinical trial of a granulocyte-macrophage colony-stimulating factor-encoding, second-generation oncolytic herpesvirus in patients with unresectable metastatic melanoma," Journal of Clinical Oncology, vol. 27, no. 34, pp. 5763-5771, 2009.
[40] A. Vigil, O. Martinez, M. A. Chua, and A. García-Sastre, "Recombinant Newcastle disease virus as a vaccine vector for cancer therapy," Molecular Therapy, vol. 16, no. 11, pp. 1883-1890, 2008.

[41] C. M. Chuang, A. Monie, A. Wu, S. I. Pai, and C. Hung, "Combination of viral oncolysis and tumor-specific immunity to control established tumors," Clinical Cancer Research, vol. 15, no. 14, pp. 4581-4588, 2009.

[42] T. Kottke, R. M. Diaz, K. Kaluza et al., "Use of biological therapy to enhance both virotherapy and adoptive T-cell therapy for cancer," Molecular Therapy, vol. 16, no. 12, pp. 1910-1918, 2008.

[43] J. Qiao, H. Wang, T. Kottke et al., "Loading of oncolytic vesicular stomatitis virus onto antigen-specific $\mathrm{T}$ cells enhances the efficacy of adoptive T-cell therapy of tumors," Gene Therapy, vol. 15, no. 8, pp. 604-616, 2008.

[44] A. Vanderplasschen, M. Hollinshead, and G. L. Smith, "Antibodies against vaccinia virus do not neutralize extracellular enveloped virus but prevent virus release from infected cells and comet formation," Journal of General Virology, vol. 78, no. 8, pp. 2041-2048, 1997.

[45] A. Vanderplasschen, E. Mathew, M. Hollinshead, R. B. Sim, and G. L. Smith, "Extracellular enveloped vaccinia virus is resistant to complement because of incorporation of host complement control proteins into its envelope," Proceedings of the National Academy of Sciences of the United States of America, vol. 95, no. 13, pp. 7544-7549, 1998.

[46] M. Hishizawa, J. Kanda, A. Utsunomiya et al., "Transplantation of allogeneic hematopoietic stem cells for adult T-cell leukemia: a nationwide retrospective study," Blood, vol.116, no. 8, pp.13691376, 2010.

[47] J. Kanda, M. Hishizawa, A. Utsunomiya et al., "Impact of graftversus-host disease on outcomes after allogeneic hematopoietic cell transplantation for adult T-cell leukemia: a retrospective cohort study," Blood, vol. 119, no. 9, pp. 2141-2148, 2012.

[48] T. Ishida, T. Joh, N. Uike et al., "Defucosylated anti-CCR4 monoclonal antibody (KW-0761) for relapsed adult T-cell leukemialymphoma: a multicenter phase II study," Journal of Clinical Oncology, vol. 30, no. 8, pp. 837-842, 2012.

[49] H. Nishikawa, Y. Maeda, T. Ishida et al., "Cancer/testis antigens are novel targets of immunotherapy for adult T-cell leukemia/lymphoma," Blood, vol. 119, no. 13, pp. 3097-3104, 2012.

[50] Y. Miyazaki, H. Fujiwara, H. Asai et al., "Development of a novel redirected T-cell-based adoptive immunotherapy targeting human telomerase reverse transcriptase for adult T-cell leukemia," Blood, vol. 121, no. 24, pp. 4894-4901, 2013. 


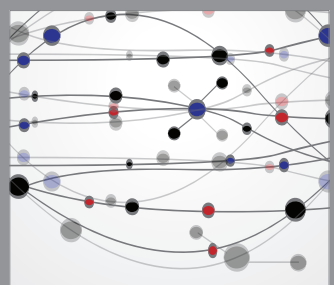

The Scientific World Journal
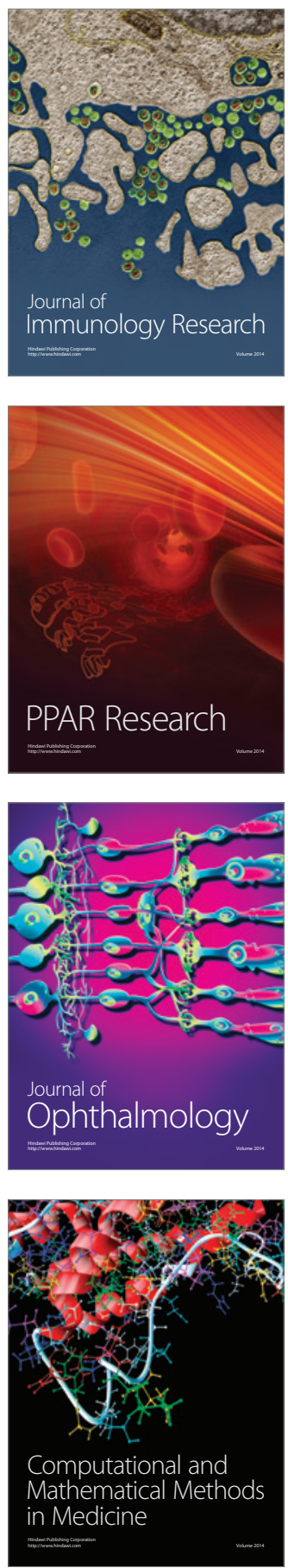

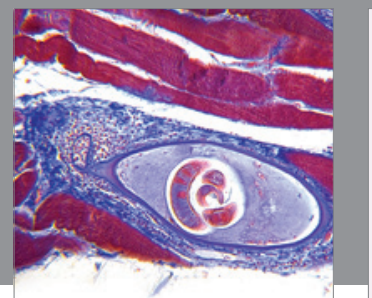

Gastroenterology

Research and Practice
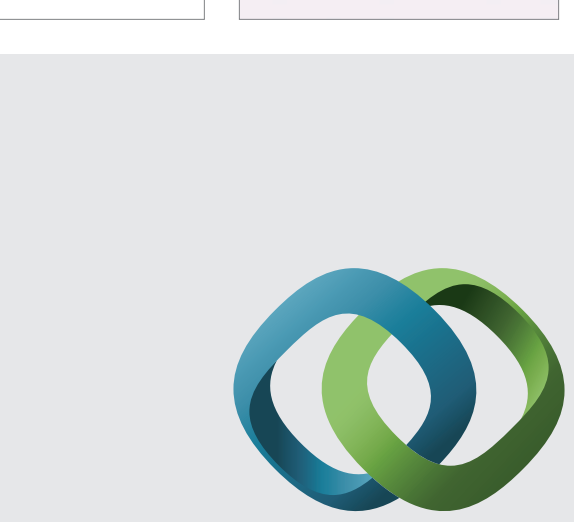

\section{Hindawi}

Submit your manuscripts at

http://www.hindawi.com
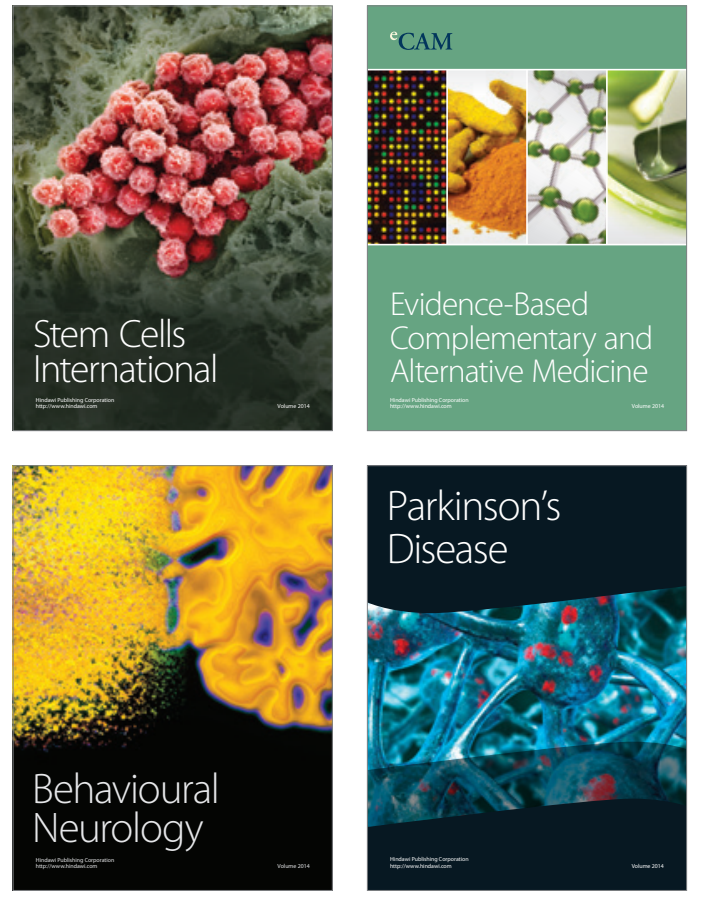
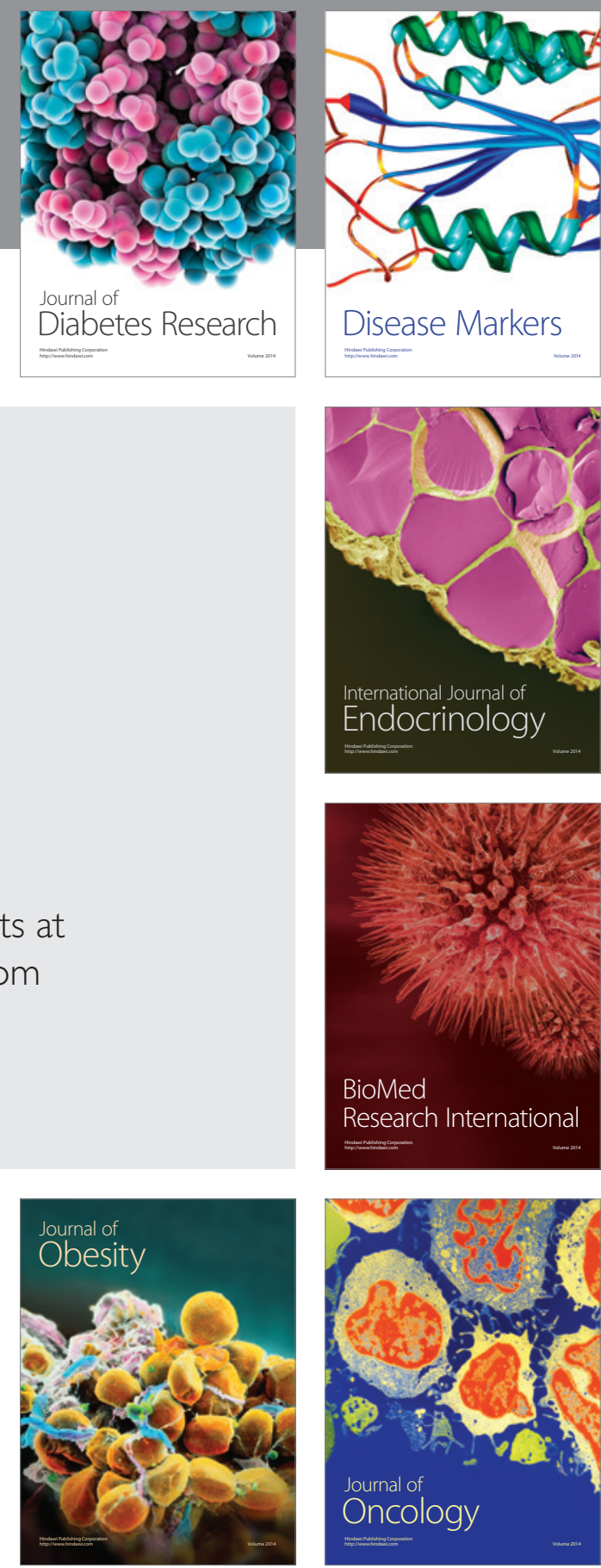

Disease Markers
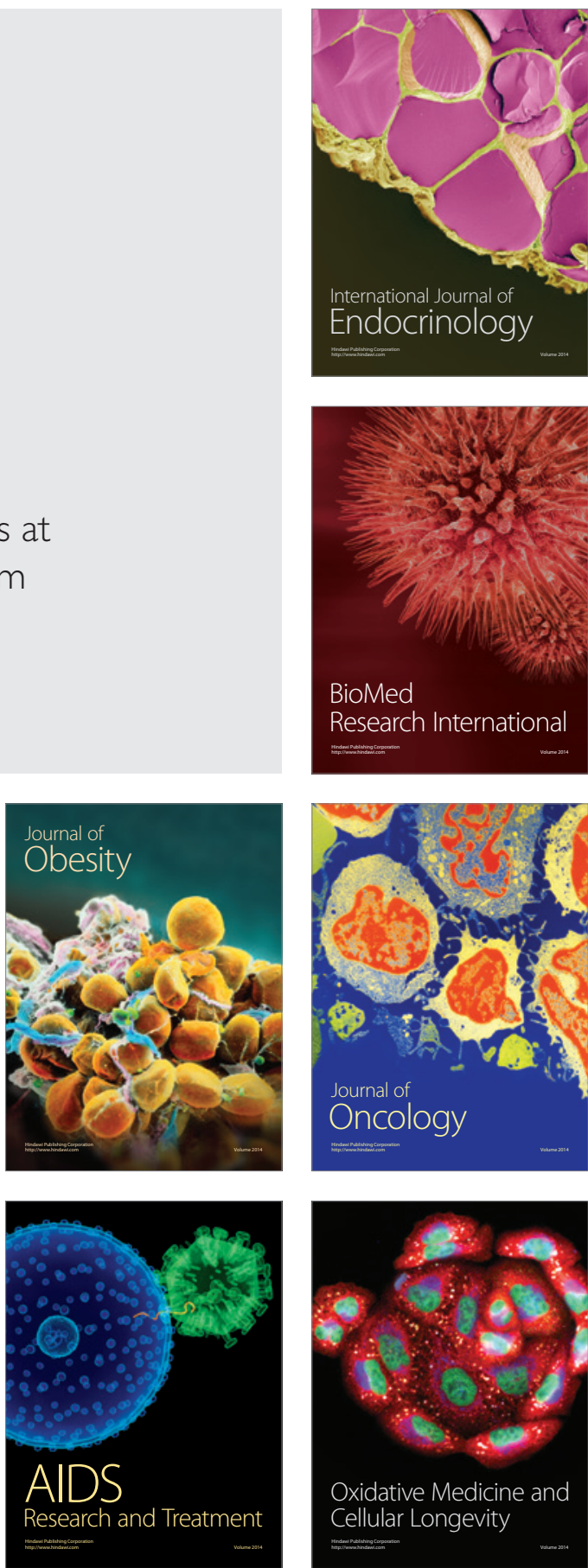